\title{
CAPN 7 promotes the migration and invasion of human endometrial stromal cell by regulating matrix metalloproteinase 2 activity
}

Hongyu Liu', Yue Jiang ${ }^{\dagger}$, Xiaoyan Jin ${ }^{\dagger}$, Lihua Zhu, Xiaoyue Shen, Qun Zhang, Bin Wang, Junxia Wang, Yali Hu, Guijun Yan* and Haixiang Sun*

\begin{abstract}
Background: Matrix metalloproteinase 2 (MMP-2) has been reported to be an important regulator of cell migration and invasion through degradation of the extracellular matrix (ECM) in many diseases, such as cancer and endometriosis. Here, we found calcium-activated neutral protease 7 (CAPN 7) expression was markedly upregulated in the eutopic endometrium and endometrial stromal cells of women diagnosed with endometriosis. Our studies were carried out to detect the effects of CAPN 7 on human endometrial stromal cell (hESC) migration and invasion.

Methods: Western blotting and quantitative real-time PCR were used to detect the expression of CAPN 7 in endometriosis patients and normal fertile women. Scratch-wound-healing and invasion chamber assay were used to investigate the role of CAPN 7 in hESC migration and invasion. Western blotting, quantitative real-time PCR and zymography were carried out to detect the effect of CAPN 7 on the expressions and activity of MMP-2.
\end{abstract}

Results: CAPN 7 was markedly up-regulated in endometriosis, thereby promoting the migration and invasion of hESC. CAPN 7 overexpression led to increased expression of MMP-2 and tissue inhibitor of metalloproteinases 2 (TIMP-2); CAPN 7 knockdown reversed these changes. CAPN 7 increased MMP-2 activity by increasing the ratio of MMP-2 to TIMP-2. We also found that OA-Hy (an MMP-2 inhibitor) decreased the effects of CAPN 7 overexpression on hESC migration and invasion by approximately $50 \%$ and $55 \%$, respectively. Additionally, a coimmunoprecipitation assay demonstrated that CAPN 7 interacted with activator protein 2a (AP-2a): an important transcription factor of MMP-2.

Conclusions: CAPN 7 promotes hESC migration and invasion by increasing the activity of MMP-2 via an increased ratio of MMP-2 to TIMP-2.

Keywords: CAPN 7, Endometrial stromal cell, Migration, Invasion

\section{Background}

Endometriosis is a common gynecological disease characterized by the presence of endometrial tissue outside the uterine cavity [1]. This disease affects approximately $10 \%$ of women of reproductive age and is associated with pelvic pain, dysmenorrhea and infertility $[1,2]$; however, the exact pathogenesis remains unclear. It has been shown that the eutopic endometrial stromal cell migration rate is higher in cells from endometriosis patients compared

\footnotetext{
*Correspondence: yanguijun55@163.com; stevensunz@163.com ${ }^{\dagger}$ Equal contributors

Reproductive Medicine Center, The Affiliated Drum Tower Hospital of Nanjing University Medical School, Nanjing 210008, Jiangsu, China
}

to endometriosis-free controls [3]. Several studies have shown that certain genes and proteins in the endometrium, including p-ERK [3], DJ-1 [4] and MMP-2 [5], are involved in endometriosis-associated proliferation, migration, invasion and angiogenesis. The aberrant expression of these proteins is a key factor in endometriosis pathogenesis.

Calpains are a family of calcium-dependent cysteine proteases that consists of more than ten mammalian gene products that are divided into two categories: classical calpains and non-classical calpains [6]. Calpains have been suggested to play important roles in many biological processes, including apoptosis and migration $[7,8]$. Aberrant calpain expression or activity is often related to serious disorders. CAPN 7, a non-classical calpain,

\section{Biomed Central}

(c) 2013 Liu et al.; licensee BioMed Central Ltd. This is an Open Access article distributed under the terms of the Creative Commons Attribution License (http://creativecommons.org/licenses/by/2.0), which permits unrestricted use, distribution, and reproduction in any medium, provided the original work is properly cited. 
lacks the EF-hand domain, and thus, its activity does not depend on $\mathrm{Ca}^{2+}[9]$; however, the exact structure and pathological significance of CAPN 7 have not been fully elucidated.

In our study, we found that CAPN 7 mRNA and protein expression was upregulated in the eutopic endometrium and endometrial stromal cells from women who were diagnosed with endometriosis, and we further investigated the effects of CAPN 7 on hESC motility and invasion.

\section{Methods}

Isolation and culture of human endometrial stromal cells HESCs were isolated from endometrial tissue obtained via endometrial biopsy from normal fertile women with regular menstrual cycles $(n=25)$ and eutopic endometrial stromal cells were isolated from eutopic endometrial of patients with pelvic endometriosis $(n=7)$. All the endometriosis patients were diagnosed by the laparoscopy and the age of the patients were 25 to 35 years old. The Drum Tower Hospital Research and Ethics Committee approved this study, and all of the patients gave their informed consent. The tissues were immediately placed into culture medium and processed according to Sun et al. [10], with minor modifications. First, the endometrial tissues were minced and enzymatically digested with $0.1 \%(\mathrm{w} / \mathrm{v})$ collagenase I (Worthington, Freehold, NJ, USA) for $30 \mathrm{~min}$ at $37^{\circ} \mathrm{C}$. Next, the digested tissues were filtered through $30 \mu \mathrm{m}$-sieve gauze to separate the stromal cells from the glands. The endometrial stromal cells were maintained in DMEM/F12 supplemented with $10 \%(\mathrm{v} / \mathrm{v}) \mathrm{FBS}, 50 \mathrm{IU} / \mathrm{mL}$ of penicillin and $50 \mu \mathrm{g} / \mathrm{mL}$ of streptomycin (Gibco BRL/Invitrogen, Carlsbad, CA, USA), seeded into culture dishes and incubated at $37^{\circ} \mathrm{C}$ in $5 \%$ $\mathrm{CO}_{2}$. The cultured stromal cells were $95 \%$ pure, as determined by vimentin staining.

\section{Adenovirus construction}

An adenovirus construct bearing the human full-length CAPN 7 gene (Ad-Flag-CAPN 7) was produced using AdMax (Microbix, Mississauga, Ontario, Canada). An adenovirus bearing LacZ (Ad-LacZ) was obtained from BD Biosciences Clontech (Palo Alto, CA, USA). The viruses were packaged and amplified in HEK293A cells and purified using $\mathrm{CsCl}$ banding, followed by dialysis against $10 \mathrm{mmol} / \mathrm{L}$ Tris-buffered saline with 10\% (w/v) glycerol. Titration was performed in HEK293A cells with the Adeno-X Rapid Titer kit (BD Biosciences Clontech) according to the manufacturer's instructions. HESCs were infected with AdLacZ or Ad-Flag-CAPN 7 at an MOI of 50.

\section{siRNA knockdown assays}

A pair of small interfering (si)RNA oligonucleotides specific for human CAPN 7 (sense strand: 5'-CAUUAGUGGUUU
CUCAAUAdTdT-3' and 3'-dTdT GUAAUCACCAAAGA GUUAU-5') and a pair of control siRNA oligonucleotides were synthesized by RIBOBIO (Guangzhou, China). HESCs were grown to $70-80 \%$ confluence and transfected with siRNAs with the SuperFectTM ${ }^{\mathrm{II}}$ (Pufei Biotech, Shanghai, China) transfection reagent at a final concentration of 50 $\mathrm{nM}$ according to the manufacturer's recommendations.

\section{Cell migration and invasion assays}

The wound and invasion assays were performed according to Rai et al. [4], with minor modifications. For the scratch wound assay, cells were starved in DMEM/ F12 plus 2.5\% (v/v) FBS for 24 hours before the assay and the cells were maintained in DMEM/F12 plus $2.5 \%$ $(\mathrm{v} / \mathrm{v})$ FBS for the entire experiment. When the cells reached $80-90 \%$ confluence, the hESCs were infected with adenovirus at $50 \mathrm{MOI}$ or transfected with $50 \mathrm{nM}$ siCTL or $50 \mathrm{nM}$ siCAPN 7. The confluent cell monolayer was wounded with a $200 \mu \mathrm{L}$ plastic cell scraper at the $0 \mathrm{~h}$ time point (immediately after siRNA transfection or $6 \mathrm{~h}$ after adenovirus infection). Cell migration was evaluated at the wound front at $0,24,48$ and $72 \mathrm{~h}$ after wounding. For the matrigel-coated invasion chamber assay, cells were also starved in DMEM/F12 plus 2.5\% $(\mathrm{v} / \mathrm{v}) \mathrm{FBS}$ for 24 hours and then infected with Ad-LacZ or Ad-Flag-CAPN 7 at an MOI of 50 or transfected with siCTL or siCAPN 7 at a final concentration of $50 \mathrm{nM}$. Polycarbonate membrane filters $(8 \mu \mathrm{m}$ pore size) (Millipore Corporation, Billerica, MA, USA) were pre-coated with matrigel. Next, the cells $\left(5 \times 10^{4}\right.$ cells per chamber $)$ in $100 \mu \mathrm{L}$ DMEM/F12 plus $0.1 \%$ (w/v) BSA were added to the top chambers. The bottom chambers were filled with $700 \mu \mathrm{L}$ DMEM/F12 supplemented with 10\% (v/v) FBS and then incubated at $37^{\circ} \mathrm{C}$ for $72 \mathrm{~h}$. Then, the invasion cells were fixed, dyed and counted. For inhibitor experiments, OA-Hy (Millipore Corporation, Billerica, MA, USA) was added at a concentration of $20 \mu \mathrm{M} 1 \mathrm{~h}$ before adenovirus infection; the OA-Hy concentration was maintained throughout the experiment. All the experiments were performed at three times and each experiment was performed with cells isolated from three patients (hESC were isolated from normal fertile women and the cultured stromal cells were $95 \%$ pure, $n=9$ ).

\section{Western blotting}

Total proteins were extracted and analyzed via western blotting as described previously [11]. HESCs and endometrium were lysed in lysis buffer $(50.0 \mathrm{mmol} / \mathrm{L}$ Tris, pH 7.6, $150.0 \mathrm{mmol} / \mathrm{L} \mathrm{NaCl}, 0.1 \%$ (w/v) SDS, 1.0\% (w/v) NP-40, protease inhibitor cocktail and phosphatase inhibitor cocktail (Sigma, St. Louis, MO, USA)). The protein concentrations in the total lysates were determined using the Bradford assay (Bio-Rad Laboratories, Hercules, CA, USA). Equal amounts of protein $(30 \mu \mathrm{g})$ were separated on 
10\% (v/v) sodium dodecyl sulfate (SDS)-polyacrylamide gel by electrophoresis for $1.5 \mathrm{~h}$, then transferred to a polyvinylidene fluoride membrane (Millipore, Billerica, MA, USA) and probed with the following antibodies as appropriate: anti-CAPN 7 (1:1000 dilution; Santa Cruz Biotechnology, CA, USA, SC-50501), anti-MMP-2 (1:1000 dilution; Bioworld Technology, MN, USA, BS1236), anti-Flag-HRP (1:2000 dilution; Sigma, St. Louis, MO, USA, A8592) and anti- $\beta$-actin (1:5000 dilution; Abcam, Cambridge, MA, USA, AP0060). An enhanced chemiluminescence kit (Amersham Biosciences Corp., Piscataway, NJ, USA) was used to visualize the blots.

\section{Co-immunoprecipitation}

Precipitations were performed as previously described [12]. Briefly, $600 \mu \mathrm{g}$ of proteins was immunoprecipitated with anti-rabbit IgG or anti-AP2 $\alpha$ (Bioworld Technology, $\mathrm{MN}, \mathrm{USA}, \mathrm{BS1015})$ at $4^{\circ} \mathrm{C}$ for $12 \mathrm{~h}$. The washed precipitates were detected by western blotting as described above.

\section{Quantitative real-time PCR}

Total RNAs were isolated using the TRIzol reagent (Invitrogen, Carlsbad, CA, USA) according to the manufacturer's instructions. Two micrograms of total RNA were subsequently reverse transcribed in a total volume of $25 \mu \mathrm{L}$ at $37^{\circ} \mathrm{C}$ for 1 hour to produce cDNA, and SYBR Green fluorescence was measured as described previously [11]. The reactions were performed using a MyiQ Single
Color Real-time PCR detection system (Bio-Rad) for $40 \mathrm{cy}$ cles $\left(95^{\circ} \mathrm{C}\right.$ for $15 \mathrm{~s}, 55^{\circ} \mathrm{C}$ for $30 \mathrm{~s}$, and $72^{\circ} \mathrm{C}$ for $\left.30 \mathrm{~s}\right)$ after an initial $3 \mathrm{~min}$ incubation at $95^{\circ} \mathrm{C}$. The specific primers used for 18S rRNA detection were $5^{\prime}$-CGGCTACCACA TCCAAGGAA-3' and 5'-CTGGAATTACCGCGGCT-3', the CAPN 7 primers were 5'-ATGGTGTCCCAAGAA AGGTG-3' and 5' 'TGGTATCCAGCCAGTCAGTG-3', the MMP-2 primers were 5'-ACATCAAGGGCATTCA GGAG-3' and 5'-ATCTCACCACGGATCTGAAC-3', and the TIMP-2 primers were $5^{\prime}$-CCAAGCAGGAGTTTCTC GAC-3' and 5'-GACCCATGGGATGAGTGTTT-3'. The efficacy of CAPN 7, MMP-2 and TIMP-2 is $90.4 \%$, 92.7\% and $100.8 \%$ respectively and the expression level of each gene was normalized against the internal reference gene $18 \mathrm{~S}$ to detect fold changes in expression. Next, melting curve and agarose gel electrophoresis analyses were used to confirm the specificity of the obtained PCR products and the real-time PCR results.

\section{MMP-2 zymography}

Gelatin zymography was performed as previously described with some modifications [13]. Supernatants were collected from hESCs treated with adenovirus or siRNA for $48 \mathrm{~h}$ in DMEM/F12 plus 2.5\% (v/v) c-FBS. Equal amounts of protein $(10 \mu \mathrm{g})$ were separated on $10 \%$ (v/v) SDS-polyacrylamide gels that contained gelatin by electrophoresis for $4 \mathrm{~h}$, then the gels were washed with $2.5 \%(\mathrm{v} / \mathrm{v})$ Triton X-100 $(2 \times 20 \mathrm{~min})$. Next, the gels were
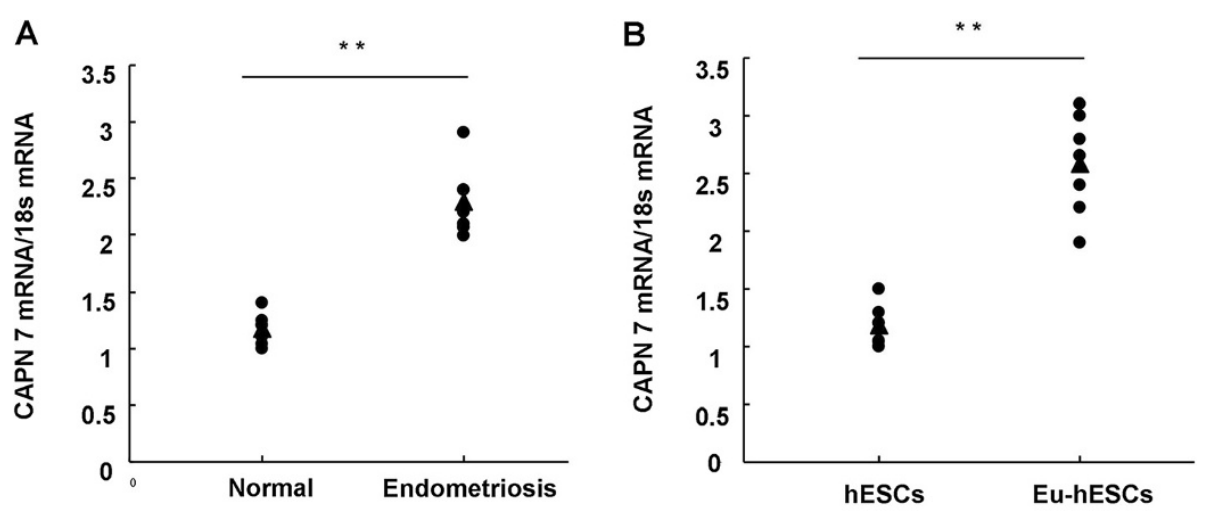

C

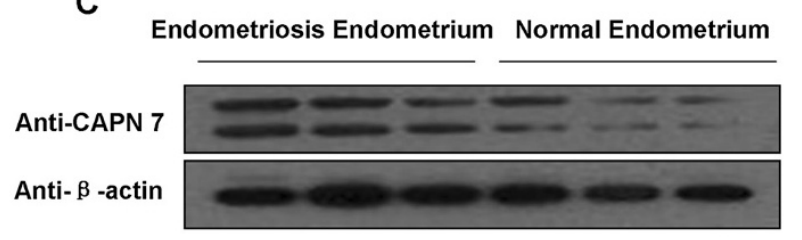

Figure 1 CAPN 7 expression in endometriosis. (A) CAPN 7 expression in the eutopic endometrium from women with endometriosis and endometrial from normal fertile controls was measured using quantitative real-time $P C R ;{ }^{*} P<0.01$ compared to the endometrium from normal fertile women ( $n=7$, triangles indicate the median expression in each group). (B) CAPN 7 expression in the eutopic endometrium stromal cells from women with endometriosis (Eu-hESCs) and hESCs from normal fertile controls was measured using quantitative real-time PCR; * * $<0.01$ compared to normal fertile women. ( $n=7$, triangles indicate the median expression in each group). (C) Western blotting results showed higher CAPN 7 protein expression in the eutopic endometrium of women with endometriosis $(n=3)$. 
incubated in a post-electrophoretic buffer $(50 \mathrm{mmol} / \mathrm{L}$ Tris, $5 \mathrm{mmol} / \mathrm{L} \mathrm{CaCl}, 200 \mathrm{mmol} / \mathrm{L} \mathrm{NaCl}$, and $3 \%(w / v)$ Brij-35) at $37^{\circ} \mathrm{C}$ for $36 \mathrm{~h}$ and stained with $0.125 \%(\mathrm{w} / \mathrm{v})$ coomassie brilliant blue for $1 \mathrm{~h}$. Finally, the gels were destained in 30\% (v/v) methanol/10\% (v/v) glacial acetic acid. Various MMPs were distinguished according to their molecular weights.

\section{Statistical analysis}

All experiments in this study were performed at least three times. Statistical analysis was performed with ANOVA, followed by the Student-Newman-Keulsmultiple comparisons test. $\mathrm{P}<0.05$ was considered statistically significant.

\section{Results}

CAPN 7 expression is increased in endometriosis

To determine the role of CAPN 7 in endometriosis, we first examined CAPN 7 expression in endometriosis patients using western blotting and quantitative real-time PCR. CAPN 7 expression was significantly higher in the eutopic endometrium and endometrial stromal cells from endometriosis patients than normal fertile subjects at both the mRNA and protein level; CAPN 7 mRNA levels were increased by more than 2-fold in endometriosis patients (Figure 1).

\section{CAPN 7 affects hESC migration and invasion}

A wound-healing assay was performed to detect the effect of CAPN 7 on hESC migration. Adenovirus-mediated CAPN 7 overexpression significantly increased hESC migration rates. Compared to the corresponding control, the migration rates increased by 1.2-, 1.3- and 1.7-fold after infection with the CAPN 7 adenovirus at 24, 48 and $72 \mathrm{~h}$, respectively (Figure 2A). However, after CAPN 7 knockdown, the migration rates decreased by $10 \%$ compared to the control at all time points (Figure 2B). CAPN 7 protein expression in the cells was further confirmed via western blotting after the wound-healing assay. We also found that CAPN 7 overexpression increased the invasiveness of hESC by approximately 2 -fold in a matrigel basement invasion assay (Figure 2C). However, CAPN 7 knockdown decreased
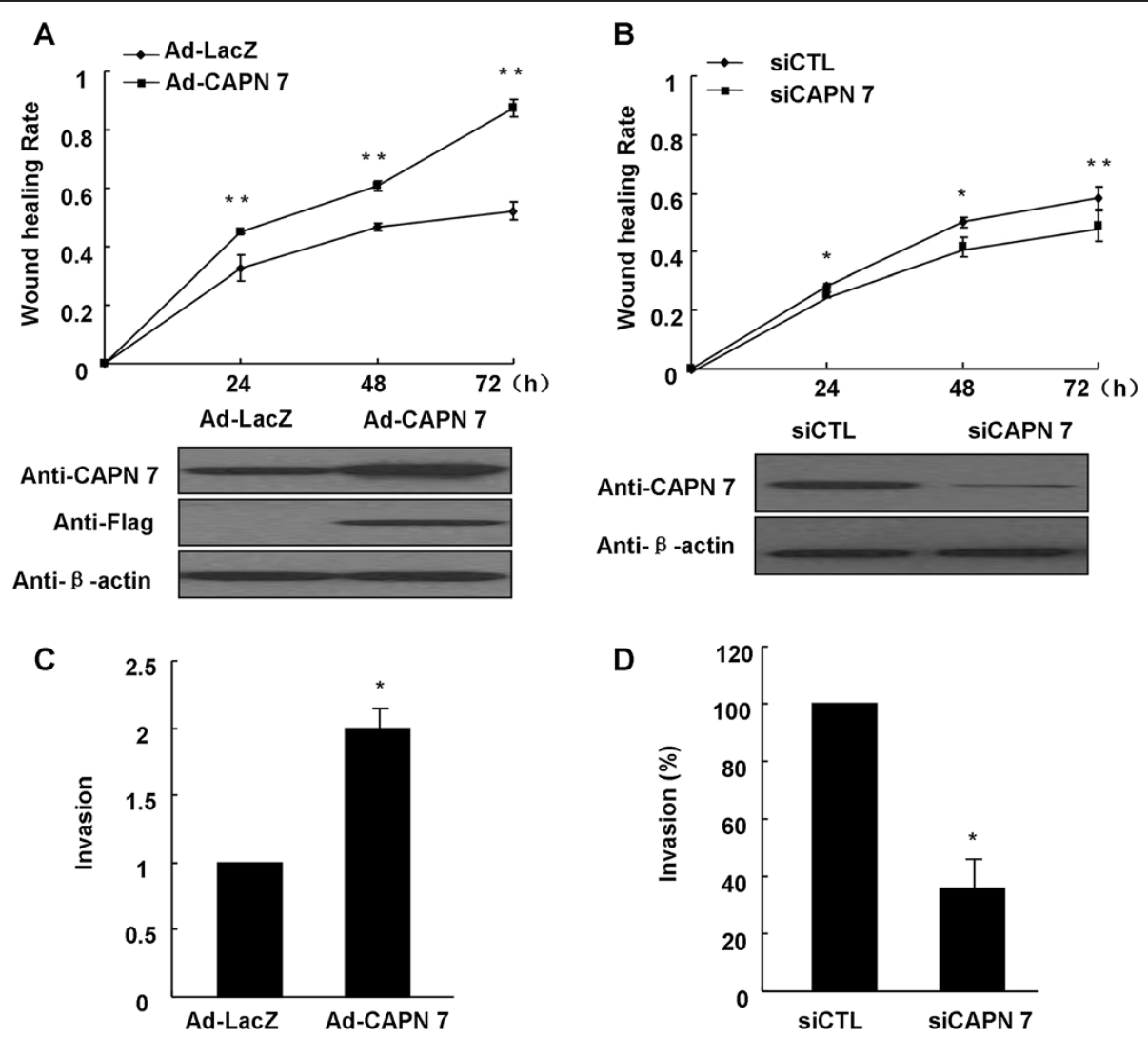

Figure 2 CAPN 7 affects hESC migration and invasion. (A) HESC were infected with Ad-LacZ or Ad-Flag-CAPN 7 (MOI=50). The migration rates (migration distance from the $0 \mathrm{~h}$ time point to a certain time) of the two groups are shown in the line graph; ${ }^{*} P<0.01$ compared with Ad-LacZ. (B) Migration rates of hESC transfected with control siRNA (siCTL) or siRNA specific for CAPN 7 (50 nM); $P<0.05$, ** $P<0.01$ compared with siCTL. (C) CAPN 7 overexpression increased cell invasion by approximately 2 -fold, ${ }^{*} P<0.05$ compared to Ad-LacZ. (D) Knockdown of endogenous CAPN 7 expression decreased cell invasion by approximately $65 \%$ compared with siCTL $(* P<0.05)$. CAPN 7 protein expression was measured by western blotting (hESC were isolated from normal fertile women, $n=9$ ). 
invasiveness by approximately $65 \%$ compared with hESC exhibiting normal CAPN 7 expression (Figure 2D).

\section{CAPN 7 overexpression upregulates MMP-2 expression and activity in hESC}

ECM degradation by matrix metalloproteinases (MMPs) is required for cell migration and invasion. MMP-2 is one of the major proteinases that play this role in the human endometrium [5]. Our results suggested that CAPN 7 overexpression increased both the expression (mRNA increased by 1.8 -fold; Figure $3 \mathrm{~A}$ and $3 \mathrm{~B}$ ) and the activity of MMP-2 (Figure 3C). Furthermore, we found that OA-Hy (an MMP-2 inhibitor) decreased the effects of CAPN 7 overexpression on hESC migration and invasion by approximately $50 \%$ and $55 \%$, respectively (Figure $3 \mathrm{D}$ and $3 \mathrm{E})$. To further quantify the role of CAPN 7, we examined TIMP-2 expression (endogenous inhibitor of MMP-2) and found that CAPN 7 overexpression increased the expression of TIMP-2 mRNA by 1.5 -fold (Figure 3F) and increased the MMP2/TIMP-2 ratio in hESC (Figure 3G). These results suggest that CAPN 7 affects the activity of MMP-2 by disrupting the balance between MMP-2 and TIMP-2, thereby regulating hESC migration and invasion. Additionally, a coimmunoprecipitation assay showed that CAPN 7 interacted with AP-2 $\alpha$ (Figure $3 \mathrm{H}$ ), suggesting that CAPN 7 regulates MMP-2 mainly at the transcriptional level. However, an in-depth study is required.

\section{Knockdown of CAPN 7 expression decreases MMP-2 expression and activity in hESC}

For an in-depth understanding of how CAPN 7 regulates hESC migration and invasion, we knocked down endogenous CAPN 7 expression in hESC. CAPN 7 knockdown reduced both the expression (mRNA decreased by $50 \%$; Figure $4 \mathrm{~A}$ and $4 \mathrm{~B}$ ) and the activity of MMP-2 (Figure 4C). Furthermore, quantitative real-time PCR

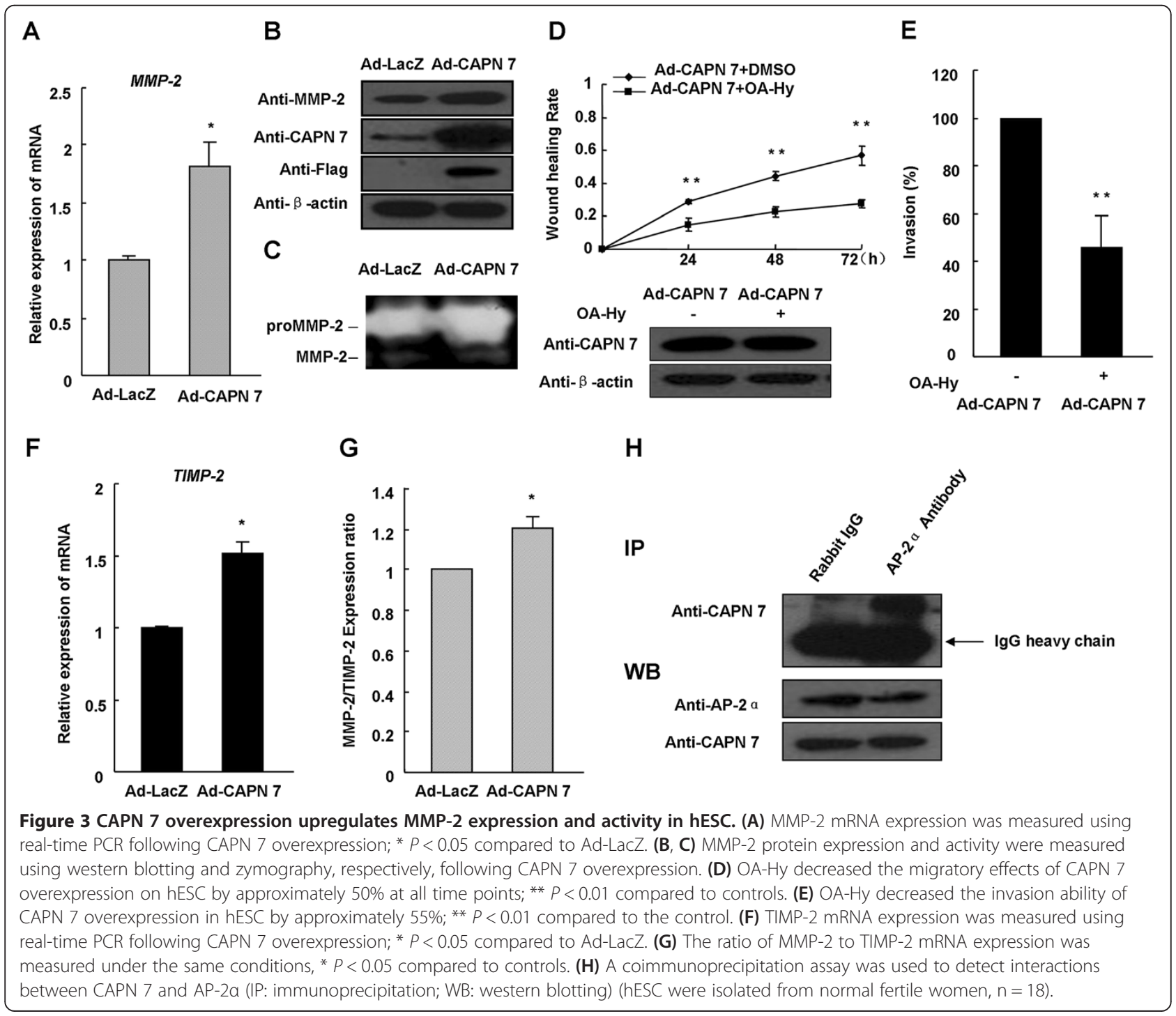




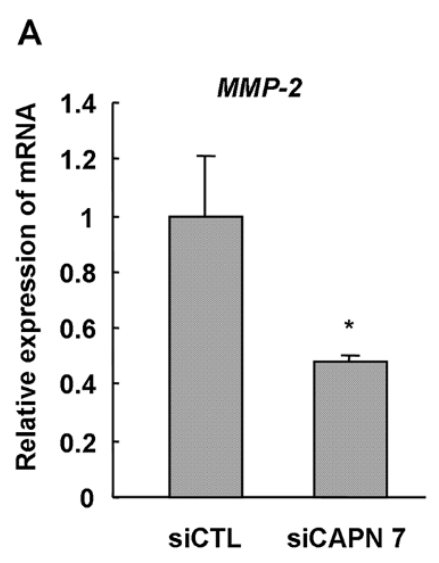

B

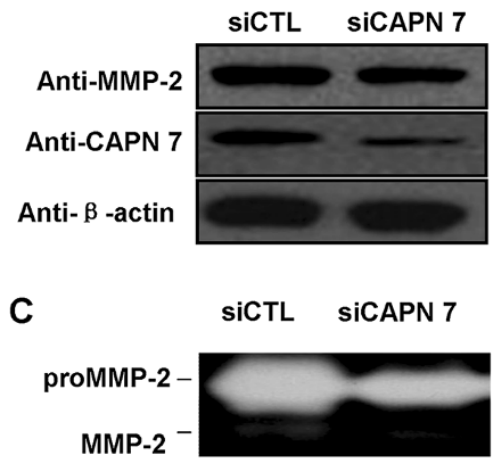

D

E
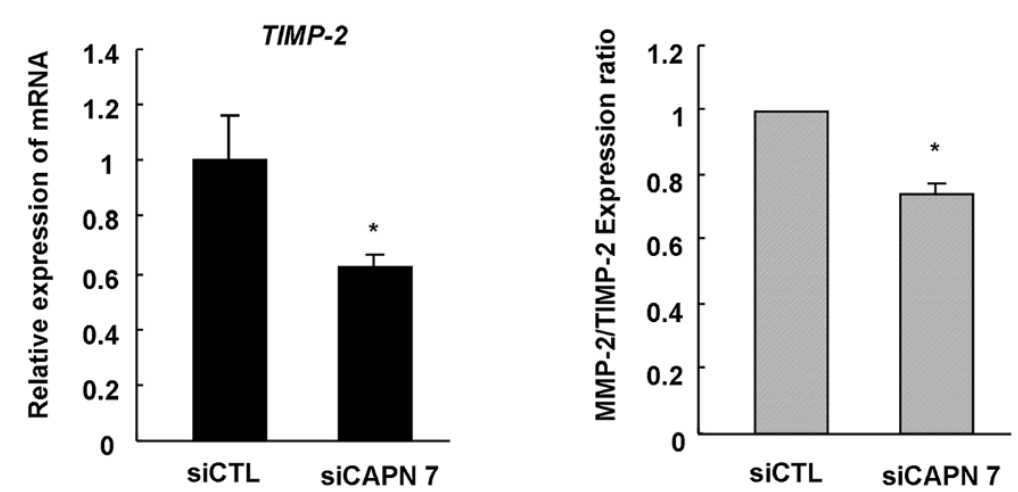

Figure 4 CAPN 7 knockdown decreases MMP-2 expression and activity in hESC. (A) MMP-2 mRNA expression was measured following CAPN 7 knockdown; * $P<0.05$ compared to siCTL. (B, C) MMP-2 protein expression and activity were measured under the same conditions. (D) TIMP-2 mRNA expression was measured following CAPN 7 knockdown; ${ }^{*}<<0.05$ compared to siCTL. (E) The ratio of MMP-2 to TIMP-2 mRNA expression was measured following CAPN 7 knockdown; $P<0.05$ compared to controls (hESC were isolated from normal fertile women, $\mathrm{n}=9$ ).

also indicated that CAPN 7 knockdown reduced the expression of TIMP-2 mRNA by $40 \%$ (Figure 4D). We observed that the inhibitory effect of CAPN 7 knockdown on MMP-2 expression was greater than the effect on TIMP-2 (Figure 4E).

\section{Discussion}

In this report, we identified the CAPN 7 regulation of MMP-2 to promote hESC migration and invasion. First, we showed that CAPN 7 expression is increased in endometriosis. CAPN 7 is a member of the calpains family, which is composed of enzymes whose activities depend on calcium [6]. Calpains have been implicated in many cellular processes, such as apoptosis and migration $[7,8]$. Aberrant calpain expression is related to a variety of diseases. For example, loss of function of the full-length isoform of calpain 3 results in limb girdle muscular dystrophy type 2A [13], knocking out alleles of mouse CAPN 8 and CAPN 9 results in ethanol-induced gastric injury [14], and aberrant calpain 10 activation results in type 2 diabetes [15]. Most importantly, the expression of calpain 6, a non- classical calpain, is increased in leiomyosarcomas [16], while the expression of calpain 5 is decreased in endometriosis [17].

Recent studies have underlined the critical role of MMP-2 in endometriosis [5]. MMP-2 belongs to the MMP family protein; these proteins play important roles in the processes of migration and invasion [18]. Our results suggested that CAPN 7 affects MMP- 2 activity by modifying the ratio of MMP-2/TIMP-2. It was previously reported that eutopic uterine endometrium from endometriosis patients had higher MMP-2 and lower TIMP-2 expression levels compared with normal fertile women [5]. Our results are not completely consistent with these reports. However, an imbalance between MMP and TIMP expression was found to be important for MMP activity and was involved in various medical conditions, including liver fibrosis and endometriosis $[5,19,20]$. Other studies have reported that TIMP-2 is unique, as it functions as both an MMP inhibitor and activator [21], meaning that it activates MMP-2 at low concentrations but inhibits MMP-2 at high concentrations [22]. It is possible 
that CAPN 7 promoted TIMP-2 expression to a low concentration and disrupted the balance between MMP-2 and TIMP-2, leading to upregulated MMP-2 activity. A previous report showed that calpain 1 and calpain 2 were involved in the adhesive and invasive abilities of osteosarcoma cells by affecting MMP-2 secretion [23]. Another study suggested that calpain 2 could affect glioblastoma cell invasion by regulating MMP-2 activity [24]. Here, we showed that CAPN 7 promotes hESC migration and invasion by increasing the activity of MMP-2; thus, it is plausible to speculate that CAPN 7 might play an important role in endometriosis.

Our findings suggested that CAPN 7 regulates MMP-2 mainly at the transcriptional level. AP- $2 \alpha$ is a member of the AP-2 family and was previously reported to affect the transcription of many genes involved in invasion and adhesion [25]. AP-2 $\alpha$ was demonstrated to enhance cell invasion by promoting MMP-2 activation [26]. Furthermore, a study on nerve growth factor reported that the AP-2-binding site was important for nerve growth factor-induced MMP-2 promoter activity [27]. Reports have indicated that calpains can degrade several transcription factors, including NF-kB [28], STAT6 [12] and P53 [29], and thus play roles in many diseases. However, whether CAPN 7 affects MMP-2 expression by degrading AP- $2 \alpha$ will be the subject of our further studies. Additionally, we analyzed the expression of matrix metalloproteinase 9 and tissue inhibitor of metalloproteinases 1 mRNA under the same conditions, but the results suggested that CAPN 7 had little effect on the expression of these genes (data not shown).

\section{Conclusions}

The present study provides the first evidence that CAPN 7 is highly expressed in endometriosis. Increased CAPN 7 expression promoted the migration and invasion of hESC by increasing the activity of MMP-2 via the increased ratio of MMP-2 to TIMP-2. Elucidating the mechanisms that underlie aberrant CAPN 7 expression in endometriosis could be of interest with regard to a better understanding of endometriosis pathogenesis and, ultimately, the development of new diagnostic tools and targeted therapies.

\footnotetext{
Abbreviations

AP-2a: Activator protein 2a; CAPN 7: Calcium-activated neutral protease 7; C-FBS: Charcoal-stripped fetal bovine serum; ECM: Extracellular matrix; FBS: Fetal bovine serum; hESC: Human endometrial stromal cell; h: Hour; MMP-2: Matrix metalloproteinase 2; MMPs: Matrix metalloproteinases; MOI: Multiplicity of infection; SDS: Sodium dodecyl sulfate; siRNA: Small interfering RNA; TIMP-2: Tissue inhibitor of metalloproteinases 2.
}

\section{Competing interests}

The authors declare that they have no competing interests.

\section{Authors' contributions}

$G Y, Y H$ and $H S$ were responsible for the conception and design of the study. $H L, Y J, X J, L Z, X S, Q Z, B W$ and JW were responsible for acquisition of data. $H L, Y J, X J, H S$ and $G Y$, performed the data analysis and drafted the manuscript. All authors participated in interpretation of the findings. YH, HS and $\mathrm{GY}$ revised and commented the draft, and all authors read and approved the final version of the manuscript. All authors confirm that the content has not been published elsewhere and does not overlap with or duplicate their published work. All authors read and approved the final manuscript.

\section{Acknowledgements}

This work was supported by a State Key Development Program for Basic Research of China Grant (973 Project No. 2010CB945104), the National Natural Science Foundation of China (No. 81170570, No. 81070508, No. 30900727, No. 81070492), a Special Grant for Principal Investigators from the Health Department of Jiangsu Province (No. XK201102, No. LJ201102, No. RC2011005), a program for the six top talents of Jiangsu Province, PR China (No. 2010-WS-058, No. 2012-WSN-005), and a Project Sponsored by the Scientific Research Foundation for Returned Overseas Chinese Scholars, State Education Ministry (No. 2011-1139).

Received: 18 March 2013 Accepted: 10 July 2013

Published: 15 July 2013

\section{References}

1. Giudice LC, Kao LC: Endometriosis. Lancet 2004, 364:1789-1799.

2. Schindler AE: Dienogest in long-term treatment of endometriosis. Int J Womens Health 2011, 3:175-184.

3. Yotova IY, Quan P, Leditznig N, Beer U, Wenzl R, Tschugguel W: Abnormal activation of Ras/Raf/MAPK and RhoA/ROCKII signalling pathways in eutopic endometrial stromal cells of patients with endometriosis. Hum Reprod 2011, 26:885-897.

4. Rai P, Shivaji S: The role of DJ-1 in the pathogenesis of endometriosis. PLoS One 2011, 6:e18074.

5. Chung HW, Lee JY, Moon HS, Hur SE, Park MH, Wen Y, Polan ML: Matrix metalloproteinase-2, membranous type 1 matrix metalloproteinase, and tissue inhibitor of metalloproteinase-2 expression in ectopic and eutopic endometrium. Fertil Steril 2002, 78:787-795.

6. Sorimachi $\mathrm{H}$, Hata S, Ono Y: Calpain chronicle-an enzyme family under multidisciplinary characterization. Proc Jpn Acad Ser B Phys Biol Sci 2011, 87:287-327

7. Ero JG, Cornut-Thibaut A, Jugé R, Debaud AL, Giménez D, Gillet G, Bonnefoy-Bérard N, Salgado J, Salles G, Aouacheria A, Kucharczak J: $\mu$ Calpain conversion of antiapoptotic Bfl-1 (BCL2A1) into a prodeath factor reveals two distinct alpha-helices inducing mitochondriamediated apoptosis. PLoS One 2012, 7:e38620.

8. Cortesio CL, Boateng LR, Piazza TM, Bennin DA, Huttenlocher A: Calpainmediated proteolysis of paxillin negatively regulates focal adhesion dynamics and cell migration. J Biol Chem 2011, 286:9998-10006.

9. Osako Y, Maemoto Y, Tanaka R, Suzuki H, Shibata H, Maki M: Autolytic activity of human calpain 7 is enhanced by ESCRT-III-related protein IST1 through MIT-MIM interaction. FEBS J 2010, 277:4412-4426.

10. Sun H, Chen L, Yan G, Wang R, Diao Z, Hu Y, Li C: HOXA10 suppresses $\mathrm{p} / \mathrm{CAF}$ promoter activity via three consecutive TTAT units in human endometrial stromal cells. Biochem Biophys Res Commun 2009, 379:16-21.

11. Jiang $Y, H u Y$, Zhao J, Zhen $X, Y a n G$, Sun $H$ : The orphan nuclear receptor Nur77 regulates decidual prolactin expression in human endometrial stromal cells. Biochem Biophys Res Commun 2011, 404:628-633.

12. Zamorano J, Rivas MD, Setien F, Perez-G M: Proteolytic regulation of activated STAT6 by calpains. J Immunol 2005, 174:2843-2848.

13. Beckmann JS, Spencer M: Calpain 3, the "gatekeeper" of proper sarcomere assembly, turnover and maintenance. Neuromuscul Disord 2008, 18:913-921.

14. Hata S, Abe M, Suzuki H, Kitamura F, Toyama-Sorimachi N, Abe K, Sakimura $\mathrm{K}$, Sorimachi $\mathrm{H}$ : Calpain $8 / \mathrm{nCL}-2$ and calpain $9 / \mathrm{nCL}-4$ constitute an active protease complex, G-calpain, involved in gastric mucosal defense. PLoS Genet 2010, 6:e1001040.

15. Norton L, Parr T, Chokkalingam K, Bardsley RG, Ye H, Bell Gl, Pelsers MM, van Loon $L$, Tsintzas K: Calpain-10 gene and protein expression in human 
skeletal muscle: effect of acute lipid-induced insulin resistance and type 2 diabetes. J Clin Endocrinol Metab 2008, 93:992-998.

16. Skubitz KM, Skubitz AP: Differential gene expression in leiomyosarcoma. Cancer 2003, 98:1029-1038.

17. Penna I, Du H, Ferriani R, Taylor HS: Calpain5 expression is decreased in endometriosis and regulated by HOXA10 in human endometrial cells. Mol Hum Reprod 2008, 14:613-618.

18. Becker CM, Louis G, Exarhopoulos A, Mechsner S, Ebert AD, Zurakowski D, Moses MA: Matrix metalloproteinases are elevated in the urine of patients with endometriosis. Fertil Steril 2010, 94:2343-2346.

19. Collette T, Maheux R, Mailloux J, Akoum A: Increased expression of matrix metalloproteinase-9 in the eutopic endometrial tissue of women with endometriosis. Hum Reprod 2006, 21:3059-3067.

20. Yang J, Zheng J, Wu L, Shi M, Zhang H, Wang X, Xia N, Wang D, Liu X, Yao L, Li Y, Dou K: NDRG2 ameliorates hepatic fibrosis by inhibiting the TGF- $\beta 1 /$ Smad pathway and altering the MMP2/TIMP2 ratio in rats. PLoS One 2011, 6:e27710.

21. Bourboulia D, Stetler-Stevenson WG: Matrix metalloproteinases (MMPs) and tissue inhibitors of metalloproteinases (TIMPs): positive and negative regulators in tumor cell adhesion. Semin Cancer Biol 2010, 20:161-168.

22. Aresu L, Benali S, Giannuzzi D, Mantovani R, Castagnaro M, Falomo ME: The role of inflammation and matrix metalloproteinases in equine endometriosis. J Vet Sci 2012, 13:171-177.

23. Fan DG, Dai JY, Tang J, Wu MM, Sun SG, Jiang JL, Fan QY: Silencing of calpain expression reduces the metastatic potential of human osteosarcoma cells. Cell Biol 2009, 33:1263-1267.

24. Jang HS, Lal S, Greenwood JA: Calpain 2 is required for glioblastoma cell invasion: regulation of matrix metalloproteinase 2. Neurochem Res 2010, 35:1796-1804.

25. Heimberger AB, McGary EC, Suki D, Ruiz M, Wang H, Fuller GN, Bar-Eli M: Loss of the AP-2alpha transcription factor is associated with the grade of human gliomas. Clin Cancer Res 2005, 11:267-272.

26. lewicz K, Sonderegger S, Haslinger P, Haider S, Saleh L, Fiala C, Pollheimer J, Knöfler M: Transcription factor AP-2a promotes EGF-dependent invasion of human trophoblast. Endocrinol 2011, 152:1458-1469.

27. Park MJ, Kwak HJ, Lee HC, Yoo DH, Park IC, Kim MS, Lee SH, Rhee CH, Hong SI: Nerve growth factor induces endothelial cell invasion and cord formation by promoting matrix metalloproteinase-2 expression through the phosphatidylinositol 3-kinase/Akt signaling pathway and AP-2 transcription factor. J Biol Chem 2007, 282:30485-30496.

28. Benayoun B, Baghdiguian S, Lajmanovich A, Bartoli M, Daniele N, Gicquel E, Bourg N, Raynaud F, Pasquier MA, Suel L, Lochmuller H, Lefranc G, Richard I: NF-kappaB-dependent expression of the antiapoptotic factor c-FLIP is regulated by calpain 3 , the protein involved in limb-girdle muscular dystrophy type 2A. FASEB J 2008, 22:1521-1529.

29. Sedarous M, Keramaris E, O'Hare M, Melloni E, Slack RS, Elce JS, Greer PA, Park DS: Calpains mediate p53 activation and neuronal death evoked by DNA damage. J Biol Chem 2003, 278:26031-26038.

doi:10.1186/1477-7827-11-64

Cite this article as: Liu et al: CAPN 7 promotes the migration and invasion of human endometrial stromal cell by regulating matrix metalloproteinase 2 activity. Reproductive Biology and Endocrinology 2013 11:64

\section{Submit your next manuscript to BioMed Central and take full advantage of:}

- Convenient online submission

- Thorough peer review

- No space constraints or color figure charges

- Immediate publication on acceptance

- Inclusion in PubMed, CAS, Scopus and Google Scholar

- Research which is freely available for redistribution 